\title{
AN OBJECT ORIENTED PERSPECTIVE FOR AC/MTDC, SYSTEM SIMULATION
}

\author{
M.R.Bhanu Prakash II.S.Clıandrasekharaiah \\ Department of High Voltage Engineering \\ Indian Institute of Science \\ Bangalore - 560012 , INDIA \\ email: bhanu@hve.iisc.ernet.in
}

\begin{abstract}
ABSTRAC'T
Object Oriented Methodology (OOM) has added a new dimension for the representation, modeling and simulation of various day-to-day applications. The basic paradigm of OOM reflects the closeness to which the methodology relates to the real world entities. Over a period of time, the requirement of detniled and exact representation with no npproximntion of real world objects that reflects its behnviornl pattern is on the rise. This has resulted in the terminology of 'Complex Objects' in system simulation. $\Lambda$ ॥ $\Lambda$ C-MTDC system has several interrelated/ interconnected components and pose a complex picture. Objectifying such system will render the system design/analysis/ identification/ performance cvaluation and control, more casy and help in better understanding of the system in its entirety. In this paper, a full representation of the various DC systems sub components are used for developing classes of components. Detailed representation along with the various attributes and methodologies associated with each of these components are represented. The case study undertaken in this paper is a Four Terminal $\mathrm{AC}$ /MTDC system with all its terminal components. The paper highlights the various advantages the OOM technique offers for Power System Modeling. This notation is of immense help especially during the system design stage wherein the tuning of various system components can be achicved without undergoing the rigor of the conventional methods.
\end{abstract}

\section{KEYWORDS :}

Object Oriented Methods (OOM), Object Oriented Design (OOI)), Object Oriented Analysis (OOA), IIVDC Transmission System, System Simulation.

\section{INTRODUCTION}

The basic building block of an DOM is an Object. An Object represents a set of data and its associated methodology/functionality bundled into a single unit. In the conventional paradigm, the data and the functions associated with the them (i.e., with data) are separated and are differenl entities. An Object is complete by itself and embeds both the data structure and the associated methods. An Object Oriented Approach is characterized by the following important properties

1.1 Class Identity : Classes are collections of objects that has common features viz., the methods and data structures. Objects are instantiation of these classes. Typically, the identification of the classes are based on the real world entities and concepts of the application of domain. The classes/objects communicate with each other by message passing paradigms. By this data duplication is avoided and changes within the objects are not propagated to other objects. The class has the following properties

- Captures the instance-of relationship between an instance and the class to which it belongs to

- Aggregates the collection of related objects
- Enhances the notion of semantic integrity.

- Factors out the specification of attributes and methods from all instances of the class into a single object. which results in saving of spaces

The attributc of the classes and the classes itself can be classified into three groups depending on the scoping required for the application

- Private Attributes/Classes

- Public Attributes/Classes

- Protected Attributes/Classes

It is these features that enables to define classes of components each with its own specific properties

1.2 Encapsulation : The property of encapsulation and the infonnation hiding allows the data structure and the implementation details of the object to be hidden from other objects/utilities in the system. To capture the cunent state of the object, message is passed onto the objects whose method on execution retrieves the information This property of obiect has madc OOM a very allractive proposition for the power system applications wherein the vililities are cross connected. 
1.3 Inheritance : Inheritance of classes lets to propagale the features of the classes not only to the objects belonging to same classes but also from other classes. This feature lermed as Multiple Inheritance. Also the inherited properties can be overridden, new features can be added, modified or appended, so that new classes can be evolved

1.4 Polymorphism : Polymorphic property refers to the ability of using the same expression to denote different operations. Polymorphism is generally implemented by what is temed as Dynamic Binding. Basically inheritance is a special kind of polymorphism that characterizes an object oriented system.

\section{MERITS OF OOM}

The above inentioned properties $(1.1-1.4)$ provide the following advantages over the conventional structured typed notation

- The Object Oriented Architecture's are Decentralized and hence it is possible to support the needs of the applications that create and managc objecls with objecl orienfed semantics.

- With the definition of classes and inheritance. concepts, it is possible to reuse code, thereby avoiding any replication of code

- With Classification being part of the system, the class strucluring provides two basic relationships: Inheritance Relationship and Client-Server Relationship. These relationships in tum build several semantically rich notions to the philosophy of object building. This being : is-a, belraves-like, implements, combines, uses, needs, has-a, consists-of relationships.

- Appropriate for desiguing objects whose complexily is high in terms cost of development, maintenance. etc.

- The basic building blocks being Object, the methods and attributes are manipulated from the requirement phase down to inplementation stage with no shif in the paradigm i.e., the OBIECT.

\section{OB.JECT ORIENTED ANALYSIS \& DESIGN METIHODOLOGY}

Analysis in general is the process of decomposition of problems into their component parts i.e., a process of specification of user requirement and system sinucture and function independently of the means of implementation or physical decomposition of modules or components. Analysis focuses on 'WHAT a system is 10 do and embodies the rule of traceability. 'WHY', which justifies the existence of given resull by tying it back to the stated goals and objectives.

On the other lrand, Design in general is an architectural inodeling that adds details, precision and inplementation dependent features to the analysis model. Designs include both Pliysical Design i.e., provides rigorous specification of the interface provided by a set of object types and Logical Design that merges with Object Oriented Analysis.

3.1 Object Oriented Analysis (OOA): Several Object Oriented Analysis techniques Sthlaer/Mellor OOSA [1], Coad/Yourdon [2][3], Rambaugh [4], SOMA[5] and several others are proposed and different tenninology are introduced, however the underlying primciples of these techniques that constitutc a $O O \wedge$ principles can be summarized as follows
- Abstract User Requirement.

- Identify Key Domain Objects.

- Assembly of those objecis into structure of a forn that will support physical design

In this paper SOM $\Lambda$, a Semantically rich Method for Object Oriented Analysis is adopted for the case under study. The main reason for the clioice of this methodology is that it incorporates all fealures of Coad/Yourdon (its simplicity), confinns with Chen's ER modeling convention and supports all structures i.e., Classification, Commosition and Associalion. In addition, lhis methodology supports Rules, which enlances the Semantic richness of the analysis model. Also it supports FUZZY OBJECTS and INHERITANCE.

Following are the major steps invoived in the analysis methodology,

- Ideniffy Layers

- Identify Objects

- Identify Structures

- Define Data Semantics and Associations

- Add attributes to Objects

- Add Operations to Objects

- Add Declarative Selmantics of the Objects

Each of these steps with a typical case study is dealt in detail in the following sections

3.2 Object Oriented Design (OOD) : Several Object Design tecluiques are available viz., Booch's6 (6), GOOD [7], HOOD [8], OOSD [9], JSD \& OOISD) 10] and Boocli'gl[11]. The methodology adopted in this paper for the object based design is based on Boocti'91 design criteria, which can be classified into foilowing steps

- IDENTIFY Classes \& INSTANCES - usually done with by either Data Flow Diagrams (DFD) 12$\}$ and/or the textual analysis[13] on the specification of the network under study. From the DFD, objects are idenlified by looking for both concrete objects and aistract objects in the problem space, objects will be found from the bubbles and data stores in the DFD. Metlods are obtained from the process bubbles. On the contrary, in textual analysis the objects, its methods and attributes are identified by identifying the grammar of the specification provided. Table 1 identifies parts of speech that is associated with various model components of the object terminology

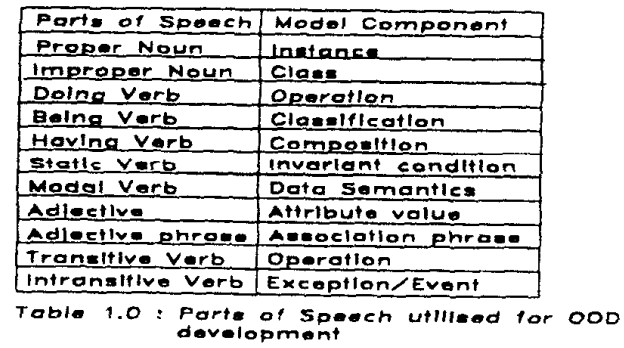

- Establishment of the Visibility of each Object IN RELATION TO OTHER OBJECTS: In this step, the definitions of the semamtics of the classes are identified and their relationship between them is identified 
- ESTABLISII TIIE INTERFACE OF EACII OBJect AND THE EXCEPTION HANDLING : Basically this step involves in the establishment of the interface that each class should have with its associated classes. By doing this step, it is possible to have proper security to the various classes. This is done by defining the classes and its attributes in any of the following categories

i) PUBLIC

ii) PRIVATE

iii) PROTECTED

- Implement and Test Objects : Implement the design as a prototype. Test the system for cohesion and consistency. Redefine the classes, instances(Objects),

Semantics and structures on the basis of what las been learnt.

\section{AN OBJECT BASED AC-MTDC SYSTEM}

The prototype system under study is a Four Terminal DC System with representation of terminal components. Fig. 1.0 represents the system under study. In this paper, a Novel Modular Converter Modeling Approach [14] is used for representing the thyristor and its triggering scheme. The network is further analyzed in [15] by using digital simulation techniques. The algorithm used for solving the system equations is Modified Euler's method and Fourth Order Runge Kutta procedure. The same analysis and design methodology are used for developing the object notation for line system . $\wedge$ step-by-step procedure involved in the development is shown. This application can be extended to any kind of electrical network.

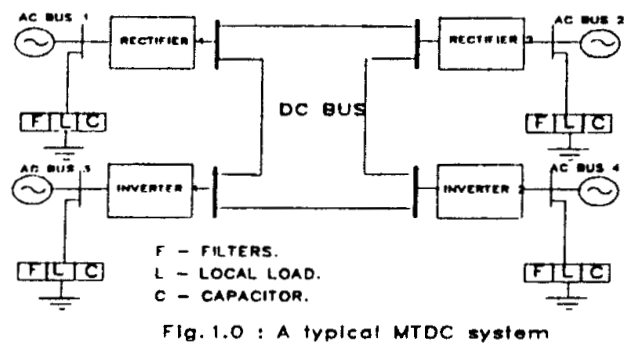

\subsection{OBJECI ORIENTED ANALYSIS (OOA)}

4.1.1 Layer Identification: Is a metlodology by which a given problem domain is decomposed. This is evolutionary step wherein changes can be made as the analysis step is performed. The Layers exist at the top of composition structures and are genuine objects themselves

in their own way. The Layers have inethods implemented by incthods of embedded objects that form a Layer, by what are termed as IMPLEMENTED-BY links. Layers in general receive and send messages and on the receipt delegate responsibilities to objects that they encapsulate. Also Layers resolves the polymorphic conflicts that might exist in the embedded objects.

For the current application, Two Layers are identified, one each representing an $\triangle C$ system and a $D C$ system. The AC system Layer or the $A C$ system Wrapper Object (can be treated as $\Lambda C$ Bus) embeds the following objects

\section{- Object SOURCE}

- Object FILTER

- Object SHUNT COMPENSATION

- Object LOAD

The DC system Layer (can be treated as DC Bus) on the other hand embeds

- Object CONVERTER TRANSFORMERS

- Object CONVERTER

- Object DC LINE

Fig. 2.0 represents the Layers identified along with the embedded objects and IMPLEMENTED-BY links. Here the term Class \& Object is used interchangeably, however the classical definition of an Object being an instantiation of the Class is maintained in its implementation and otherwise

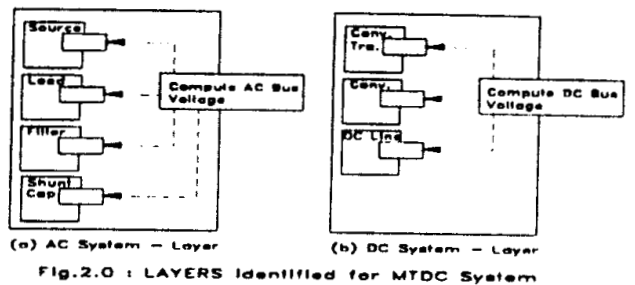

4.1.2 Structure Identification: Structure Identification can be classified as

- Usage Structure

- Classification Structure

- Composition Structure

- Association Structure

4.1.2.1 Usage Structure : This structure records the message passing topology of the system. By building the usage structure, it is possible to reduce the complexity of the structure. The Behavioral model of the objects and their interaction will be the outcome of Inilding a Usage structure.

Fig. 3.0 reflects the usage struclure or the interlinks of various objects of the system under consideration. The Fig.3.0 shown is for a typical single $A C$ and $D C$ system interface. The same principle is extended for the MTDC systeın.

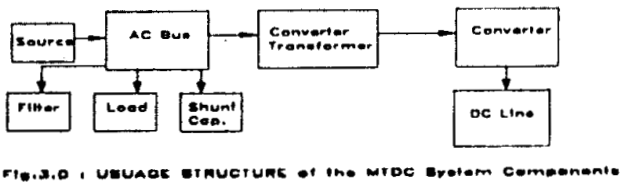

4.1.2.2 Classification Structure : The classification structure records the several underlying semantics of the typical class hierarchies that are logical outcome of the instantiation of the classes. The attributes of classification structure must contain the specinl attributes : $\wedge$ Kind of (AKO) : attribute and MEMBER:attribute. Multiple Inheritance and Disjunctive Inheritance can be reflected in the classification structure. Other relations that can be reflected are

- E/O or Exclusive Optional : indicate that each subclass's intersection with the other subclass is emply.

- I/O or Inclusive Optional : indicate the subclass may overlap.

- Optional : indicate that list is not exciusive, llicre may be more as yet identified subclasses. 
- Mandalory : indicate that a memberof the super class must be atleast one of the subclasses.

All AKO relationships are Many-to-One association. Fig 4.0 represents the classification structure of the typical Filter Class along with its associations.

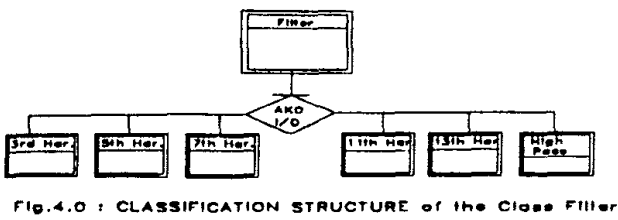

4.1.2.3 Composition Structure : must contain A Part of (APO):attribute and Parts: attribute. These attributes are used as the navigational tools. The composition links can be interpreted at both Class and Object level. Like classification structure, relations $\mathrm{E} / \mathrm{O}, \mathrm{I} / \mathrm{O}, \mathrm{O}$ and $\mathrm{M}$ can be used but parts do nol overinp.

Fig. 5.0 represents the composition structure for the Class Filter. Likewise all the composition structure for all the other classes were developed

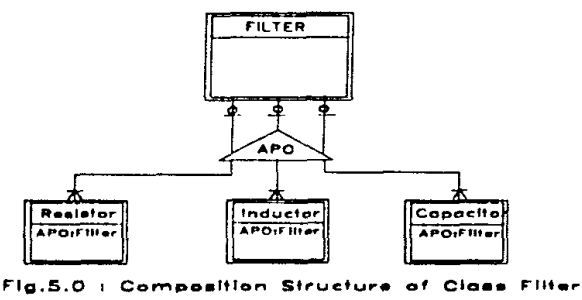

4.1.2.4 Association Structure : is structural relationship other than Usage, Classification and Composition. OMT is used for identified composition structure and association structures.

4.1.3 Object Identification: Several methodologies viz., Coad/Yourdon, Shlear/Meller, Objectory Case Usc [5], State Transition Models (STD) are used for the object identification. Fig. 6.0 shows Data Flow Diagram (DFD) from which objects are inferred from the bubbles and data stores.

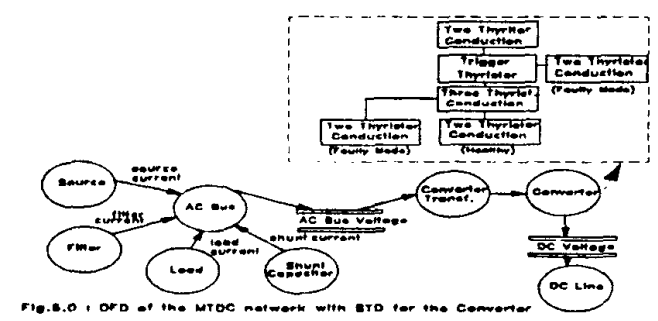

4.1.4 Addlition of Attribute to Objects : From the various structures identified, AKO:attribute and Part:attribute (List-Attributes) form the attribute of the object under consideration. Also APO:attribute and Member:attribute also form the attributes of the object. Altributes in general are

- Pure Attributes - Defined (ADTs) or Primitive Ones

- Association Attribute

Typical attribute list along with the simulation parameters associated with the converter is slown in Fig. 7.0, lisese attributes are identified from both structures and DFDs
4.1.5 Addition of Methods: The Methods/Operalions govern the behavior of the object and its interaction (Message Passing) with olher objects. The Methods are identified by STDs and DFDs of the system. From the DFDs, the process bubbles correspond to the methods of the objects. Some of the typical methods associated with the Class Converter if shown in Fig. 7.0

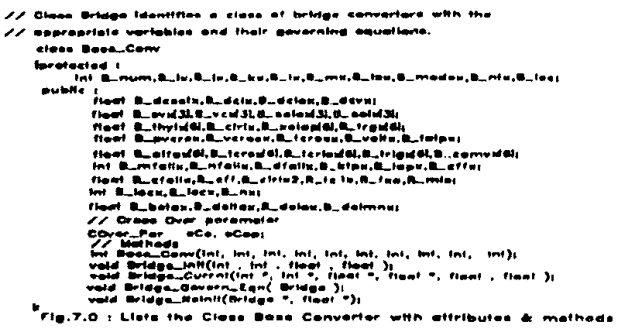

4.1.6 Addition of Data Semiantics to the Objects : Data Semantics to the Objects is reflecled by incorpornting RULES to the objects. A Rule Window interface provided with each of the objects enables to incorporate the associated rules to the object. Rules aid in disambiguating the Multiple Inheritance Conflicts and also define the priority for the objects. Like altributes and methods, rules may be inherited and overridden, with local variation possible. Decision Tree is used to describe a complex set of rules. In the present study, simple assertions are added to the Class PI Controller. The Class Converter in lurn inherits these nules from the Class PI Controller.

\subsection{OBJECT ORIENTED DESIGN (OOD)}

4.2.1 Identification of Classes and Instances: This step in design overlaps with the analysis methods, it is this advantage that makes the OOD methods attractive for varied applications. This step acts as a measure for devolving the classification of the problem domain further The DFDs developed are used for object identification. For the current application, following classes are developed.

Fig.8.0 reflects the class hierarchy developed for the current study. Class Converter inlierits its properties from the Class Base Converter, Class Conventional Controller and from the Class Intelligent Controller. The implementation is done such that one of the controlter is instantiated for a given converter

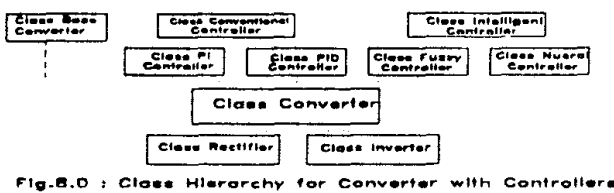

4.2.2 Establishment of the visibility of the Objects All the classes developed for the current application was declared global, however certain attributes of classes were declared as private members. Some attributes were deciared as protecled members in order access the values down the class hierarchy. This step offers security for object management and is useful for interlinked utilities.

4.2.3 Establishment of the interface for each of the Object \& Exception llandling : $\wedge$ simple filc based interface for handling both dymamic and constant 
parameters of the network was provided. The Overloaded consiructor methods provided for each of the classes further enhanced the interface part for eacli of the classes. Exception Handling included in the current implementation is provided by standard $\mathrm{C}++$ features viz., throw, calcl and try.

4.2.4 Test and Implement Objects : The progran implementation is done using $\mathrm{C}++$. Several case studies were conducted and each of these results was checked with slandard bench mark models. Fig. 9.0 lists the various class hierarchies developed for the four terninal systems

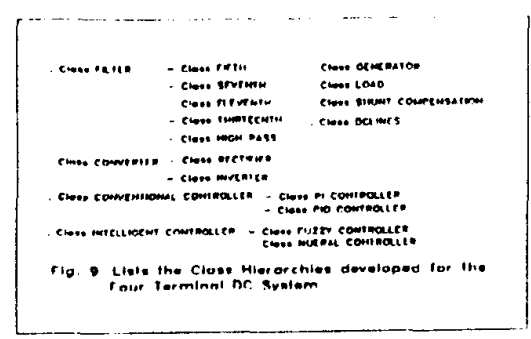

Taking the particular class hierarchies into consideration the steady state characteristics at terminals of the MTDC system is deternnined and is as shown in Fig.10.0 -16.0. Similar characteristics can also be determined at the other tenninals very easily because of the object methodology.

\subsection{CONCLUSIONS}

An Object notation is developed in this paper for the simulation of Four Terminal MTDC system along with the tenninal components. An Object notation offers a mechanism that brings the model closer to its real world entity. The data hiding and data abstraction that forms the heart of object notation, offers a secure ellvironment especially for cross-linked utilities. Also the network connectivity could be inferred by navigating the class hierarchies and class links. This notation further aids the data handling mechanison in real time that is currently under investigation.

\subsection{REFERENCES}

[I] S.SHLAER \& S.J.MELLOR, 'Object Oricnled Sysicms Analysis - Modeling the world in data', Englewood Cliffs, NJ:Yourdon Press, 1988.

[2] P.COAD \& E.Yourdon, 'Object Oriented Analysis' 2nd Edition, Englewood Cliffs, NJ, Yordon Press/Prentice Hall, 1991.

[3] P.Coad \& E.Yourdon, 'Object Oriented Analysis', Englewood Cliffs, NJ, Yourdon Press/Prentice Hall, 1991.

[4] J.Rambaugh, '(Ohject Oriented Modeling and Design', Prentice Hall, Englewood Cliffs, 1991.

[5] I.M.Graham, 'Migrating 10 Object techmology', Wokingham, Addison-Wesley, 1994.

[6] Grady BooCH, 'Object (Oriented Development', IEEE Trans. on Soflware Engineering, Vol SE-12(2), 211 221,1986 .
[7] SEIDwITz \& STARK, ' (ieneral Ohject Oriented Development', Software Ëngineering Letters, 86-002, 1986.

[8] P.ROBINSON, 'Object Oriented Design', London:Chapman and Hall.

[9] Wasseman, Pircher,et.al, ' The Ohject Oriented Structured Isesign', IEEE Computer, pp 50-62, March 1990.

[10]M.A.JACKson, 'System Developmen', Englewood Cliffs N.J, Prentice Hall, 1983.

[11] Graby BOOCH, 'Ohject (Oriented Design with Applications', CA, Benajmin Cummings, 1991.

[12] EDWARd Yourdon, 'Modem Siructured Analysis', Yourdon Press, Englewood Cliffs, NJ, 1989

[13] R.J.ABBOTT, 'Program Design by Informal linglish Descriptions', Comınunication of ACM, 26(1), 882-894, 1983.

[14] M.MuRgesh Mudaliar \& H.S.CHANDRASEKharaiah, 'Dynamic Digilal Simulalion of HVIC : sys/oms usimg a Novel Modular Converter Model', IEEE Trans. on PAS, Vol. No.10, Oct 1985, pp 2852-2856.

[15]PREMILAMANOHAR,H.S.CHANDRASEKHARAIAH, 'Artificial Commutation for inversion into a weak $A C^{\circ}$ system in Multiterminal $H V I) C$ system',Electric Power System Research, Vol.19, No.2, pp. 95-104, 1990.
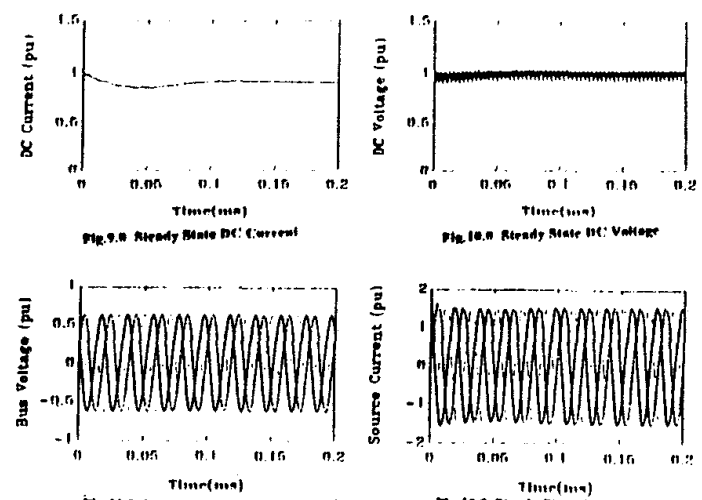

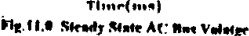

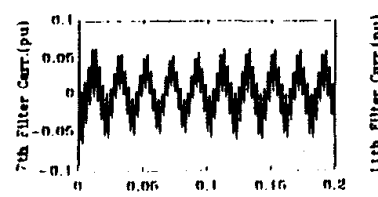

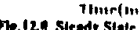

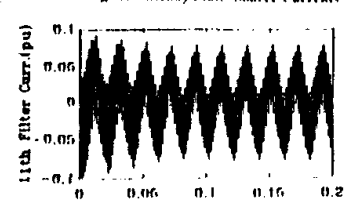

Tiner(m)

timerimes)

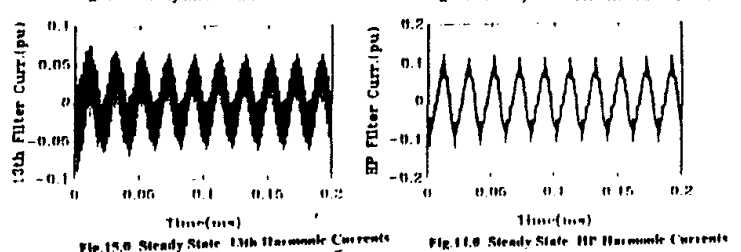

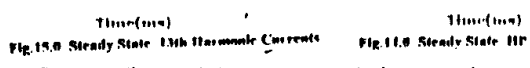

Note : System Clintactetistics in a terminal penetsled with the Object Oricuted Methedolngy based on a maliculat clase hierachies developerl. 